\title{
Anodic oxidation of oleate for wastewater treatment
}

\author{
M. Gonçalves ${ }^{\mathrm{a}}$, A. Joyce ${ }^{\mathrm{a}}$, M. Alves ${ }^{\mathrm{b}}$, J.P. Correia ${ }^{\mathrm{a}, \mathrm{c}}$, I.P. Marques ${ }^{\mathrm{a}, *}$ \\ ${ }^{a}$ Departmento de Energias Renováveis, INETI, Est. Paço do Lumiar, 1649-038 Lisboa, Portugal \\ Tel. +35121 7127209; Fax +351217127195; email: isabel.paula@ineti.pt \\ ${ }^{b}$ Centro de Engenharia Biológica, Universidade do Minho, 4710-057 Braga, Portugal \\ ${ }^{c} C Q B$, Faculdade de Ciências da Universidade de Lisboa, 1749-016 Lisboa, Portugal
}

Received 28 April 2005; accepted 5 May 2005

\begin{abstract}
The anodic conversion of oleate was carried out on $\mathrm{RuO}_{2}$ type DSA electrode under potentiostatic control. It was used as a pre-treatment of the anaerobic degradation of oleate, which is a long chain fatty acid abundant in wastewaters. Electrochemical treatment was found to improve the anaerobic biodegradation of lipidic wastewaters. In batch experiments, pre-treated oleate was converted to methane without any lag phase, whereas the onset of oleate mineralization was delayed by $90 \mathrm{~h}$. Additionally, the rate of methane production was higher in the pre-treated oleate batch assays than in the oleate ones.
\end{abstract}

Keywords: Oleate; Electrooxidation; Lipids; Anaerobic Digestion; Biodegradation

\section{Introduction}

Lipids are attractive substrates for anaerobic digestion due to the higher methane yield obtained, when compared to proteins or carbohydrates. They constitute an important part of organic matter in effluents and can be considered as a large potential renewable energy. Lipids are easily hydrolyzed to long chain fatty acids (LCFA) which are potentially inhibitory to the bacterial groups

\footnotetext{
*Corresponding author.
}

involved in LCFA degradation (acetogenic and methanogenic bacteria). Lipids give also rise to biomass flotation and reactor washout by forming a lipid layer around the bacterial aggregates [1,2].

Conventional pre-treatment technologies are commonly applied to eliminate these problems but they present some relevant disadvantages. Physical separation of fat removes the potential methane production associated to this fraction of organic matter and dissolved and/or emulsified quantities are not efficiently removed remaining in the

Presented at the Conference on Desalination and the Environment, Santa Margherita, Italy, 22-26 May 2005.

European Desalination Society.

0011-9164/05/\$- See front matter (C) 2005 Elsevier B.V. All rights reserved.

doi:10.1016/j.desal.2005.05.011 
wastewater [3]. Chemical technologies that are based on the addition of chemical reactants represent additional costs and sludge production.

Anodic oxidation is an interesting alternative, especially because it can be used as a pre-treatment technology in detoxifying ahead of bio-treatment, rather than mineralizing them completely. Electrochemical methods have been successfully applied to treat a wide variety of organic wastes, i.e. phenolic [4], azo-dyes [5] textile [6,7], and olive oil [8].

The anodic oxidation reactions have in common the fact that they involve transfer of O-atoms from $\mathrm{H}_{2} \mathrm{O}$ in the solvent phase to the oxidation products. Johnson et al. [9] explained anodic oxidation of various organic compounds on the basis of the following mechanistic speculations: (1) a prerequisite of the required anodic O-transfer reactions is the discharge of $\mathrm{H}_{2} \mathrm{O}$ to generate adsorbed hydroxyl radicals; (2) a co-requisite is preadsorption of the reactant species; (3) the O-transfer step occurs from $(\mathrm{OH})_{\mathrm{ads}}$ to $(\mathrm{R})_{\mathrm{ads}}$; and (4) an inevitable but undesirable concomitant reaction is the anodic evolution of $\mathrm{O}_{2}(\mathrm{~g})$.

Therefore, variations in reactivity of electrode materials are ascribed to differences in the extent of electrocatalytic participation of these electrode surfaces within the anodic O-transfer mechanisms [9]. The excellent electrocatalytic activity of Dimensionally Stable Anodes (DSA) [10] makes these electrodes as promising materials to carry out the electrochemical conversion. Recent investigations have concluded that ruthenium dioxide type DSA's are efficient in various organic wastes degradation [4,6,7].

The objective of the present work is to study the efficiency of the electrochemical treatment of oleate using a $\mathrm{RuO}_{2}$ type DSA in alkaline medium. Batch experiments were performed to evaluate the effect of electrochemical treatment on oleate biodegradation and toxicity.

\section{Materials and methods}

\subsection{Voltammetric study}

Voltammetric measurements were performed in a three electrode two compartment cell using an EG\&G Princeton Applied Research model 273 potentiostat/galvanostat. The experiments were carried out in alkaline solutions $(0.1 \mathrm{M} \mathrm{NaOH})$ and in the presence of $10 \mathrm{~g} / \mathrm{L}$ sodium oleate, which was used as a model compound. A platinum foil counter electrode and a saturated calomel reference electrode (SCE) were used. The working electrode was $\mathrm{RuO}_{2}$ type DSA electrode (geometric area $=0.7 \mathrm{~cm}^{2}$ ). The electrooxidation of oleate was studied voltammetrically in the potential range of $0<\mathrm{E}<1.5 \mathrm{~V}$ vs. SCE at the scan rates of 10 and $100 \mathrm{mV} \mathrm{s}^{-1}$.

\subsection{Electrooxidation of oleate: electrolysis experiments at constant potential}

Electrolysis experiments were performed using the conditions established in the voltammetric study. They were carried out under potentiostatic control using a DC power supply (Unilab) being the anode potential controlled against the reference electrode by a voltmeter. The cathode was a stainless steel sheet, being employed the same electrode used in the voltammetric runs as anode (geometric area $=1.4 \mathrm{~cm}^{2}$ ). A $0.02 \mathrm{~L}$ volume solution of $10 \mathrm{~g} / \mathrm{L}$ sodium oleate $(\mathrm{NaOH} 0.2 \mathrm{M})$ was used. Current values were monitored along the $28 \mathrm{~h}$ of total electrolysis time.

\subsection{Methanogenic activity and biodegradabil- ity batch experiments}

Methanogenic activity, toxicity and biodegradability batch experiments were performed 
using a pressure transducer technique [11]. These tests involve monitoring the pressure increase developed in sealed vials, maintained under strict anaerobic conditions. The hand held pressure transducer was capable of measuring a pressure increase or decrease of two bar $(0-50 \mathrm{kPa})$ over a range of -50 to $+50 \mathrm{mV}$. The sensing element consists of a $2.5 \mathrm{~mm}$ square silicon chip with integral sensing diaphragm and is connected to a digital panel meter module. The device is powered by a $7.5 \mathrm{~V}$ DC transformer. The basal medium used in the batch experiments is composed of cysteine-HCL $(0.5 \mathrm{~g} / \mathrm{L})$ and sodium bicarbonate $(3 \mathrm{~g} / \mathrm{L})$ and made up with demineralized water. It is prepared under strict anaerobic conditions and the $\mathrm{pH}$ is adjusted to 7.0-7.2 with $\mathrm{NaOH} 8 \mathrm{~N}$. No calcium or trace-nutrients were added.

The methanogenic activity tests were performed in duplicate assays by using nongaseous substrates (acetate, propionate, butyrate and ethanol). In the methanogenic toxicity tests, the oleate concentration was $0.1 \mathrm{~g} / \mathrm{L}$ and acetate was added as co-substrate, in order to evaluate the influence of oleate and of electrochemical product on the acetoclastic activity. Toxicity tests were performed in triplicate assays. Biodegradability tests were carried out by adding $0.5 \mathrm{~g} / \mathrm{L}$ of oleate before and after electrochemical treatment to the sludge in batch vials. They were performed in duplicate assays. Methane production was corrected for standard temperature (STP) conditions.

The suspended sludge used in experiments was obtained from a laboratory anaerobic filter fed with skim milk as substrate. Table 1 summarizes the results of the specific methanogenic activity against acetate, propionate, butyrate and ethanol. Concerning the methanogenic activity against propionate, butyrate and ethanol, it should be noted that these substrates are indirect methanogenic
Table 1

Methanogenic activity of biomass used in the biodegradability and toxicity batch experiments

Methanogenic activity in the presence of: $(\mathrm{mL}$ $\left.\mathrm{CH}_{(\mathrm{STP})} \mathrm{gVSS}^{-1} \mathrm{~d}^{-1}\right)^{\mathrm{a}, \mathrm{b}}$

\begin{tabular}{ll}
\hline Acetate & $16.9 \pm 2.9$ \\
Propionate & $23.3 \pm 0.4$ \\
Butyrate & $19.7 \pm 1.0$ \\
Ethanol & $96.5 \pm 5.6$
\end{tabular}

${ }^{\text {a }}$ Methane $\left(\mathrm{CH}_{4}\right)$ at standard temperature and pressure.

${ }^{\mathrm{b}} \pm 95 \%$ confidence interval.

substrates and a valid measurement of the maximum specific methanogenic activity against these acids can only be obtained when the acetoclastic and hydrogenophilic activities are not rate-limiting [12]. In the present sludge, however, the acetoclastic activity was limiting the overall rate of methane production from the indirect substrates.

\section{Results and discussion}

\subsection{Electrochemical experiments}

Fig. 1 depicts the cyclic voltammograms in a wide potential range of the DSA electrode in alkaline solutions in the presence and in the absence of sodium oleate. The current increase noticed at ca. $0.6 \mathrm{~V}$ in the $\mathrm{NAOH}$ solution corresponds to the oxygen evolution reaction (OER). As in the oleate free solution, in the lipid containing media the same onset potential to the anodic current be observed is recorded. However, in this case, lower current values are obtained at higher potential values likely due to the adsorption of the lipid at the electrode surface. Being so, the oxidation of oleate would occur by direct electron transfer with the electrode or through a redox reaction with the evolved oxygen. At the higher scan rate (Fig. 1b) the current magnitudes at high anodic potentials 

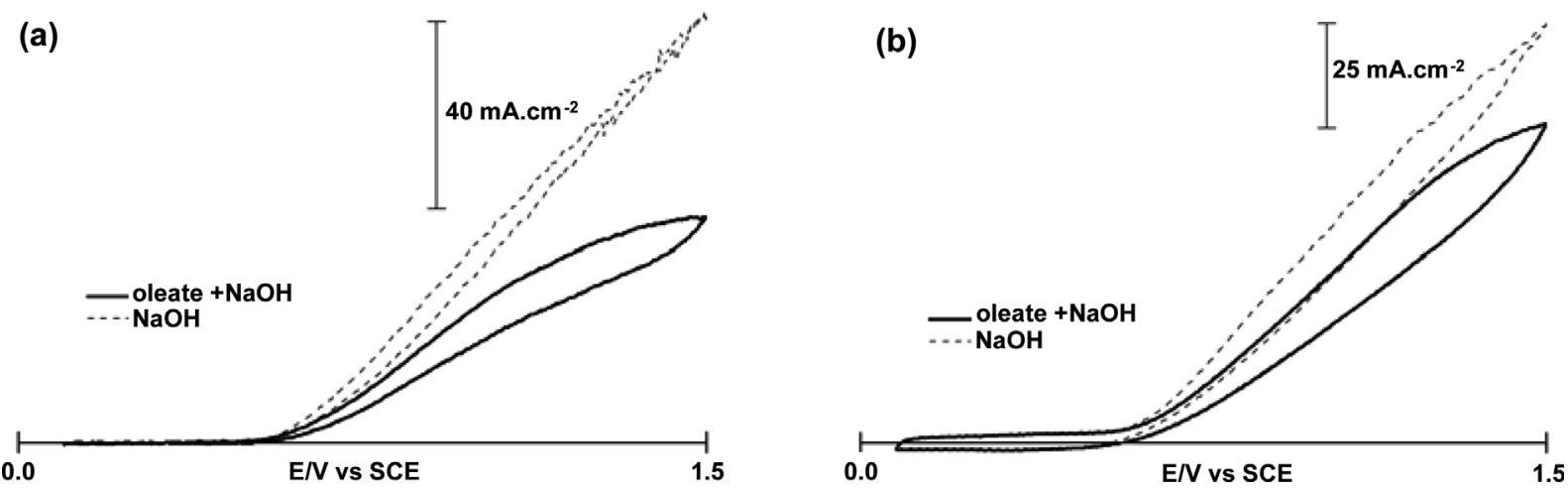

Fig. 1. Cyclic voltammograms of a $\mathrm{RuO}_{2}$ type DSA electrode in $0.1 \mathrm{M} \mathrm{NaOH}$ solutions in the presence $(-)$ and absence (---) of (a) $10 \mathrm{~g} / \mathrm{L}$ sodium oleate at $\mathrm{n}=10$ and (b) $100 \mathrm{mV} \mathrm{s}^{-1}$.

in both solutions are not as different as observed at the lower sweep rate (Fig. 1a). This feature can probably be ascribed to a slow adsorption process of the oleate species. Indeed, if the water molecules adsorbs faster at the electrode than the oleate (after releasing of the reaction products) the monitored current should approach that obtained in the $\mathrm{NaOH}$ solution, as observed.

In order to avoid excessive oxygen generation and at the same time keep the current values at significant values, a constant potential of $1.2 \mathrm{~V}$ vs. SCE was chosen to perform the long run electrolysis experiments.

\subsection{Biodegradability and toxicity batch experiments}

Cumulative methane production pattern when oleate and electrooxidation product were anaerobic degraded is presented in Fig. 2.

For electrochemical product no lag phase was observed before the onset of methane production and therefore, the initial rate of methane production from product was higher than the observed for oleate. The maximum plateau achieved was not significantly different among the two substrates thereby suggesting that COD was not substantially reduced by the pre-treatment method which is advantageous as far as the global methane yield is concerned.

The results obtained from toxicity batch experiments showed a toxic effect on the acetoclastic activity against both tested substrates [Fig. 3]. Nevertheless, this effect was more important for the raw oleate than for electrochemical product. The pre-treatment has exerted an advantageous effect since the potential oleate toxicity was decreased.

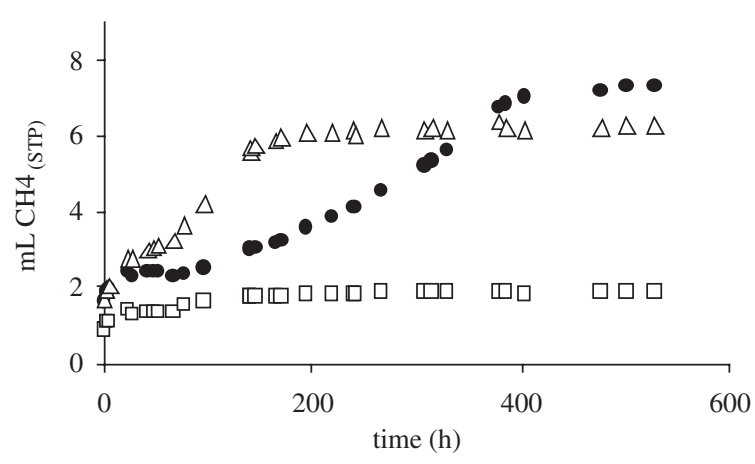

Fig. 2. Biodegradability tests. Cumulative methane production due to the biodegradation of oleate before $(\bullet)$ and after $(\Delta)$ electrochemical treatment, for a concentration of $0.5 \mathrm{~g} / \mathrm{L}$, and in the blank control assay $(\square)$. 


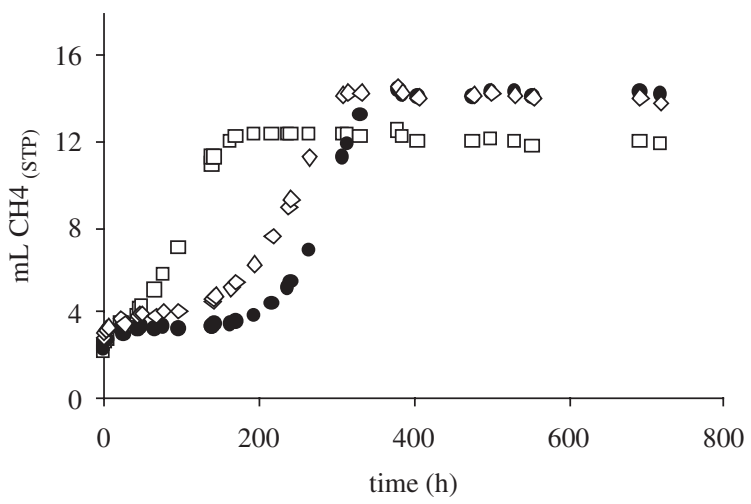

Fig. 3. Toxicity tests. $(\square)$ control; oleate before $(\bullet)$ and after $(\diamond)$ electrochemical treatment for a concentration of $0.1 \mathrm{~g} / \mathrm{L}$.

\section{Conclusions}

Oleate as other LCFA exerts a detrimental effect on anaerobic process and it conversion can be improved by electrochemical pre-treatment using a $\mathrm{RuO}_{2}$ type DSA.

The potential toxic effect of oleate on the acetoclastic activity is reduced by the electrochemical process. On the other hand, the biodegradability batch experiments revealed that the pre-treated oleate is faster converted than the raw oleate. The electrochemical treatment was beneficial, since the initial rate of methane production from the pre-treated oleate was higher than the observed for oleate.

\section{Acknowledgements}

This research was financial supported by Fundação para a Ciência e Tecnologia (Project: POCTI/2001/CTA/41642). The authors acknowledge ELTECH Systems Corporation for kindly providing the Dimensional Stable Anodes used in this work

\section{References}

[1] I.W. Koster and A. Cramer, Inhibition of methanogenesis from acetate in granular sludge by LCFA, Appl. Environ. Microbiol., 53 (1987) 403-409.
[2] A. Rinzema, M. Boone, K. van Knippenberg and G. Lettinga, Bactericidal effect of long chain fatty acids in anaerobic digestion, Water Environ. Res., 66(1) (1994) 40-49.

[3] L. Masse, K.J. Kennedy and S. Chou, Testing of alkaline and enzymatic hydrolysis pretreatments for fat particles in slaughterhouse wastewater, Bioresource Technol., 77(2) (2001) 145-155.

[4] Y.J. Feng and X.Y. Li, Electro-catalytic oxidation of phenol on several metal-oxide electrodes in aqueous solution, Water Res., 37 (2003) 2339-2407.

[5] M. Panizza and G. Cerisola, Influence of anode material on the electrochemical oxidation of 2naphthol. Part 2. Bulk electrolysis experiments, Electrochimica Acta, 49 (2004) 3221-3226.

[6] S. Kim, T.-H. Kim, C. Park and E.-B. Shin, Electrochemical oxidation of polyvinyl alcohol using a $\mathrm{RuO}_{2} / \mathrm{Ti}$ anode, Desalination, 155 (2003) 49-57.

[7] N. Mohan, N. Balasubramanian and V. Subramanian, Electrochemical treatment of stimulated textile effluent, Chem. Eng. Technol., 24(7) (2001) 749-753.

[8] C.J. Israilides, A.G. Vlyssides, V.N. Mourafeti and G. Karvouni, Olive oil wastewater treatment with the use of an electrolysis system, Bioresource Technol., 61 (1997) 163-170.

[9] D. Johnson, J. Feng and L. Houk, Direct electrochemical degradation of organic wastes in aqueous media, Electrochimica Acta, 46 (2000) 323-330.

[10] S. Trasatti, Electrocatalysis: understanding the success of DSA $^{\circledR}$, Electrochimica Acta, 45 (2000) 2377-2385.

[11] E. Colleran, F. Concannon, T. Goldem, F. Geoghegan, B. Crumlish, E. Killilea, M. Henry and J. Coates, Use of methanogenic activity tests to characterize anaerobic sludges, screen for anaerobic biodegradability and determine toxicity thresholds against individual anaerobic trophic groups and species, Water Sci. Technol., 25 (1992) 31-40.

[12] J. Dolfing and W.G.B.M. Bloemen, Activity measurements as a tool characterize the microbial composition of methanogenic environments, J. Microbiol. Methods, 4 (1985) $1-12$. 